Journal of Social Sciences 1 (3): 156-161, 2005

ISSN 1549-3652

(C) 2005 Science Publications

\title{
Food Attitudes towards Food Safety Concept among Turkish University Students
}

\author{
${ }^{1}$ Nihat Aycan, ${ }^{2}$ Suat Türkoğuz and ${ }^{3}$ Özlem Tokuşoğlu \\ ${ }^{1}$ Applied Sciences Institute, Celal Bayar University, 45040, Manisa, Turkey \\ ${ }^{2}$ Education Faculty, Dokuz Eylül University, 35100, Buca, Izmir, Turkey \\ ${ }^{3}$ Celal Bayar University, Akhisar M.Y.O., 45200, Manisa, Turkey
}

\begin{abstract}
This study investigated university students' food choices focusing on their reported usual intake and food safety perceptions and conducted at Manisa Celal Bayar University Engineering Faculty, Science and Art Faculty and Education Faculty students. The present study primary investigated how affects the storage style, manufacturing qualification, shelf life and food safety concept, advertisement effect on consuming, natural and fortificated foods to university students. Meanwhile, faculty differences, sex (male, female) and age differences, living area, family features (parent living style, education, brother and sister number etc.) of students were determined. In addition, consuming frequency of extensively consumed beverages (soft drinks, cola, tea, coffee, alcoholic drinks) and bread as main consuming food were investigated based on sex and faculty criteria as daily, weekly, monthly.
\end{abstract}

Key words: Food attitudes, food safety, university students, sex, age, living conditions, fruit juices, alcoholic and soft drinks, bread

\section{INTRODUCTION}

Humans need various foods to protect their existence based upon time and environment due to foods fulfills not only biological necessities of humans but also meets their cultural and social needs ${ }^{[1]}$. The basic principle behind the Food Guide Pyramid is to remember to eat a variety of foods and to maintain a healthy balance ${ }^{[2,3]}$. Although social environment, which in persons live, affect their nutrition attitudes, social culture can be a main factor in food perceptions. Acceptation or rejection of a food reflects human interactions. Due to an unsuitability in food attitudes such as excessive and inadequate nourishment, one-side nourishment result in unbalanced nutrition, this acceptation or rejection has been annoyed both persons and their connected people. Food habits affect social behaviors and perceptions ${ }^{[4,5]}$. Food attitudes and expectations among university students is important because university has been formed most intellectual class of society. In this context, it should determine the attitudes and behaviors regarding foods and food safety concept in university students.

This study investigated university students' food choices focusing on their reported usual intake and food safety perceptions and conducted at Manisa Celal Bayar University Engineering Faculty, Science and Art Faculty and Education Faculty students. The present study primary investigated how affects the storage style, manufacturing qualification, shelf life and food safety concept, advertisement effect on consuming,

natural foods and fortificated foods including artificial ingredients to university students. Meanwhile, faculty differences, sex (male, female) of students were determined. Additionally, consuming frequency of extensively consumed beverages (soft drinks, cola, tea, coffee, alcoholic drinks) and bread as main consuming food were investigated based on sex and faculty criteria as daily, weekly, monthly.

\section{MATERIALS AND METHODS}

This study was carried out at Manisa Celal Bayar University Engineering Faculty (Food Engineering), Science and Art Faculty (Chemistry, Biology, Physic Departments) and Education Faculty (Science education) all last class students. The questionnaire was conducted to 88 last class students of Science and Art Faculty, 24 last class students of Food Engineering and 177 last class students of Education Faculty last class students as totally 289 respondents.

The developed questionnaire with uncovered extremity and likert scale by Aycan, Türkoğuz and Tokuşoğlu includes fact variables such as faculty differences, sex (male, female) and age difference, living area, family features (parent living style, education, brother and sister number etc.), consuming frequency of extensively consumed beverages and bread as daily, weekly, monthly and judgment variables such as storage style, manufacturing qualification, shelf-life and food safety concept, advertisement effect on consuming, natural foods and fortificated foods including artificial ingredients and food advertisements.

Data analysis with fact and judgment variables was evaluated by using SPSS (Ver.10, Windows Statistical Package Program). Multiple regression analysis of data

Corresponding Author: Nihat Aycan, Applied Sciences Institute, Celal Bayar University, 45040, Manisa, Turkey, Tel: 009023624121 56, Fax: 00902362412158 
belong to last class students of Food Engineering, last class students of and Science and Art Faculty and last class students of Education Faculty were conducted by t-test and ANOVA as a source of variables. All data were declared in frequency tables.

\section{RESULTS}

Each fact and judgment questions were given as individual tables to report data as concrete via systematic scalar. Data that has multiply meaning was given as nine table and others were report in text. Table 1 shows university student opinions regarding food safety knowledge according to faculty difference.

It is determined that university students are generally unstable regarding food protection $(x=3.34)$. Concerning food protection in refrigerator university students display unstable attitude $\left(\mathrm{x}_{=} 3.22\right)$, they report same attitude regarding food protection with glass packing $(\mathrm{x}=4.35)$. University students' report that food products have not been protected appropriate temperatures $(\mathrm{x}=2.34)$ and seller people not known protection temperature $\left(\mathrm{x}_{=} 1.18\right)$. In addition, they report that food products protection with metal $(\mathrm{x}=1.23)$ and plastic $(\mathrm{x}=1.28)$ packing is dangerous in consuming.

It is established that university students has same attitude regarding marketplace of food products and they report suitable of marketplaces $\left(x_{=}=4.16\right)$. Meanwhile they report that food products should sell individually $(\mathrm{x}=4.23)$, selling area should be clear and safety $(x=3.94)$, aeration $(x=4.52)$, inspected $(x=4.73)$ and seller people should be experienced ( $x=4.40)$. Also, they suggest that shopping should be in supermarkets and hypermarkets $(x=4.17)$. Students display unstable attitude concerning shopping and buying from buffet and market $(\mathrm{x}=2.99)$.

University students exhibit generally unstable attitude regarding warnings necessity in all food labels $(\mathrm{x}=2.85)$. They also display unstable attitudes regarding kind of warning in labels $(\mathrm{x}=1.37)$ and especially warnings in food labels should be written clearly $(\mathrm{x}=3.13)$.

However, the concept regarding the appropriate labeling $(\mathrm{x}=3.55)$ and suitable coding system $(\mathrm{x}=3.80)$ on the food products is dominant. This labeling including "warning" $(\mathrm{x}=2.10)$ and "shelf life and expiration date" $(\mathrm{x}=2.42)$ is not in appropriate visible area of food product and also those of are not legible $(\mathrm{x}=2.34)$.

Students demonstrate the unstable attitude concerning food advertisements in TV $(x=2.92)$. They report that advertisements not increase the product quality $(\mathrm{x}=2.22)$ and only increase the product inflection $(x=4.16)$. They also exhibit that there are advertisements regarding the artificial food products $(\mathrm{x}=3.84)$. They put forward that it is not always suitable consuming the advertisable food products $(x=2.20)$ and Table 1: The effect of faculty difference on food safety knowledge of university students it is not always problem consuming the nonadvertisable food products $(x=2.35)$. University students exhibit that product quality not always based on the advertisement $(x=2.23)$ and they report that advertisements raise the appetite $(\mathrm{x}=3,47)$.

Students exhibit the unstable attitude regarding artificial food products and have generally negative tendency to artificial food products ( $\mathrm{x}=2.44)$. According to them, it is harmful the consuming the fast food type food products $(x=1.78)$ and affect the human health as negative $(x=2.45)$. In addition, they report that it is harmful the most consuming above-mentioned artificial foods $(x=2.20)$ due to these not include the natural constituents $(x=2.48)$ and they also report that they are unstable attitude concerning the less consuming $(x=2.85)$. Moreover, their common opinion are reported that artificial food products and fast food type foods affect the Turkish Food and Cuisine Culture $(\mathrm{x}=2.12)$.

Expiration date on food products is always true $(x=3.16)$, labeling procedure on food products is always safe $(x=3.12)$ based on food safety concept. Students not always trust in the food products with advertisement $(\mathrm{x}=2,48)$, food products with stately $(\mathrm{x}=1,85)$, food seller $(\mathrm{x}=2.44)$ and expiration date on food products $(x=3.45)$. They only trust in the packaged foods $(x=3.86)$.

According to faculty differences, food safety concept has been varied (Table 1). Science and Art Faculty (Chemistry, Biology, Physic Departments) students exhibit the unsatisfied attitude regarding warnings and labeling formats on food products whereas Engineering Faculty (Food Engineering) exhibit the unstable position. According to Science and Art Faculty and Education Faculty (Science education) students, advertisements not increase the food product quality whereas Food Engineering students exhibit unstable attitude in this matter. Science and Art Faculty and Engineering Faculty (Food Engineering) student's thinks that advertisements increase the appetite whereas Education Faculty (Science education) students are unstable in this matter. Engineering Faculty (Food Engineering) students trust in the information details on the food labels whereas other faculty students exhibit unstable attitude regarding food label details. There are no significant differences between faculties $(p>0.01)$ concerning food preservation, hygienic conditions in food manufacturing area, warnings on food labels and food concept (Table 1).

As shown in Table 2, 25\% of students generally not consume cola whereas woman's consume as $21.7 \%$ and mans consume as $27 \%$. Cola consuming in students in Education Faculty is more than that of the others (Table 2). 


\begin{tabular}{|c|c|c|c|c|c|}
\hline \multirow{3}{*}{ Opinions } & \multicolumn{3}{|l|}{ Faculty } & \multirow{3}{*}{$\mathrm{F}$} & \multirow{3}{*}{ SD } \\
\hline & $\begin{array}{l}\text { Science } \\
\text { Faculty (n:88) }\end{array}$ & $\begin{array}{l}\text { Education } \\
\text { Faculty (n:177) }\end{array}$ & $\begin{array}{l}\text { Engineering Food } \\
\text { Eng.Faculty(n:24) }\end{array}$ & & \\
\hline & $\mathrm{x}$ & $\mathrm{x}$ & $\mathrm{x}$ & & \\
\hline Warnings in food label satisfy to consumers & 2.46 & 2.80 & 3.13 & 3.52 & 0.03 \\
\hline Advertisement increase food product quality & 2.00 & 2.24 & 2.88 & 3.64 & 0.03 \\
\hline We should consume food products with most advertisement & 1.92 & 2.30 & 2.50 & 3.57 & 0.03 \\
\hline All food advertisement may increase appetite & 3.65 & 3.29 & 4.13 & 5.88 & 0.00 \\
\hline Details in food label are trustable & 2.82 & 3.19 & 3.67 & 6.25 & 0.00 \\
\hline Artificial food products must most consumable & 1.58 & 1.93 & 1.38 & 3.98 & 0.02 \\
\hline Food storage process is important & 3.32 & 3.36 & 3.29 & 0.21 & 0.81 \\
\hline Food marketplace and selling area are important & 4.11 & 4.16 & 4.25 & 0.38 & 0.69 \\
\hline Food labelling is important & 2.76 & 2.86 & 3.08 & 2.16 & 0.12 \\
\hline Food advertisement quality in media is important & 2.83 & 2.94 & 3.09 & 1.53 & 0.22 \\
\hline Food safety conscience & 2.76 & 2.96 & 3.08 & 1.76 & 0.27 \\
\hline HACCP is important in food safety & 3.02 & 2.98 & 3.06 & 1.44 & 0.20 \\
\hline
\end{tabular}

Table 2: Cola consuming ratio as weekly (acc.to faculty and sex)

\begin{tabular}{|c|c|c|c|c|c|c|}
\hline \multirow[b]{2}{*}{ Liter } & \multicolumn{6}{|c|}{ Cola amounts (weekly consumption) } \\
\hline & $0.5-1 \mathrm{lt}$ & Less 1-2 lt & 2 lt and over & No & No reply & Total \\
\hline \multirow[t]{2}{*}{$\overline{\text { Male }}$} & 21 & 61 & 22 & 21 & 4 & 129 \\
\hline & $16.30 \%$ & $47.30 \%$ & $17.10 \%$ & $16.30 \%$ & $3.10 \%$ & $100.00 \%$ \\
\hline \multirow[t]{2}{*}{ Female } & 27 & 62 & 15 & 51 & 5 & 160 \\
\hline & $16.90 \%$ & $38.80 \%$ & $9.40 \%$ & $31.90 \%$ & $3.10 \%$ & $100.00 \%$ \\
\hline \multirow[t]{2}{*}{ Education Fac. } & 22 & 79 & 27 & 49 & - & 177 \\
\hline & $12.40 \%$ & $44.60 \%$ & $15.30 \%$ & $27.70 \%$ & - & $100.00 \%$ \\
\hline \multirow[t]{2}{*}{ Science-Art Fac. } & 20 & 33 & 9 & 18 & 7 & 87 \\
\hline & $23.00 \%$ & $37.90 \%$ & $10.30 \%$ & $20.70 \%$ & $8.00 \%$ & $100.00 \%$ \\
\hline \multirow{2}{*}{ Eng.Fac. } & 6 & 10 & 1 & 5 & 2 & 24 \\
\hline & $25.00 \%$ & $41.70 \%$ & $4.20 \%$ & $20.80 \%$ & $8.30 \%$ & $100.00 \%$ \\
\hline \multirow[t]{2}{*}{ General } & 48 & 123 & 37 & 72 & 9 & 289 \\
\hline & $16.60 \%$ & $42.60 \%$ & $12.80 \%$ & $24.90 \%$ & $3.10 \%$ & $100.00 \%$ \\
\hline
\end{tabular}

Table 3: Tea consuming ratio as weekly (acc. to faculty and sex)

\begin{tabular}{|c|c|c|c|c|c|c|}
\hline \multirow[b]{2}{*}{ Tea cup (40 mL) } & \multicolumn{6}{|c|}{ Tea amounts (weekly consumption) } \\
\hline & No & $1-3$ cup & 4-7 cup & 7 cup and over & No reply & Total \\
\hline \multirow[t]{2}{*}{ Male } & 3 & 48 & 51 & 24 & 3 & 129 \\
\hline & $2.30 \%$ & $37.20 \%$ & $39.50 \%$ & $18.60 \%$ & $2.30 \%$ & $100.00 \%$ \\
\hline \multirow[t]{2}{*}{ Female } & 8 & 81 & 49 & 17 & 5 & 160 \\
\hline & $5.00 \%$ & $50.60 \%$ & $30.60 \%$ & $10.60 \%$ & $3.10 \%$ & $100.00 \%$ \\
\hline \multirow[t]{2}{*}{ Education Fac. } & 3 & 83 & 62 & 29 & - & 177 \\
\hline & $1.70 \%$ & $46.90 \%$ & $35.00 \%$ & $16.40 \%$ & - & $100.00 \%$ \\
\hline \multirow[t]{2}{*}{ Science-Art Fac. } & 6 & 33 & 30 & 12 & 6 & 87 \\
\hline & $6.90 \%$ & $37.90 \%$ & $34.50 \%$ & $13.80 \%$ & $6.90 \%$ & $100.00 \%$ \\
\hline \multirow[t]{2}{*}{ Eng.Fac. } & 2 & 12 & 8 & - & 2 & 24 \\
\hline & $8.30 \%$ & $50.00 \%$ & $33.30 \%$ & - & $8.30 \%$ & $100.00 \%$ \\
\hline \multirow[t]{2}{*}{ General } & 11 & 129 & 100 & 41 & 8 & 289 \\
\hline & $3.80 \%$ & $44.60 \%$ & $34.60 \%$ & $14.20 \%$ & $2.80 \%$ & $100.00 \%$ \\
\hline
\end{tabular}

It is shown that, $3.8 \%$ of students generally not consume tea. Woman's consume tea as $92 \%$ and mans consume as $95 \%$. Based on the faculty criteria, it is determined that tea consuming in students in Engineering Faculty (Food Engineering), Science and Art Faculty (Chemistry, Biology, Physic Departments) is $85 \%$ level and tea consuming in students in Education Faculty is $98 \%$ level (Table 3).

As shown in Table $4,71 \%$ of students consume fruit juices and soft drink. Based on the sex criteria, woman's consume as $68 \%$ and mans consume as $75 \%$. Based on the faculty criteria, fruit juices and soft drink consuming in students in Education Faculty is $75 \%$ of level whereas that of in students in Science and Art Table 4: Fruit juice and soft drinks consuming ratio as weekly (acc. to faculty and sex)
Faculty is $62 \%$ of level and that of in Engineering Faculty is $75 \%$ (Table 4).

It is reported that, $91 \%$ of students generally consume bread in their nutrition. This level is extremely high. Based on the sex criteria, woman's consume bread as $86 \%$ and mans consume as $98 \%$. Based on the faculty criteria, bread consuming in students in Education Faculty (Science Education) is $95 \%$ of level, in Engineering Faculty (Food Engineering) is $88 \%$ of level and Science and Art Faculty (Chemistry, Biology, Physic Departments) is $84 \%$ level of total consuming (Table 5). 


\begin{tabular}{|c|c|c|c|c|c|c|}
\hline \multirow[b]{2}{*}{ Liter } & \multicolumn{6}{|c|}{ Fruit juices and soft drink amounts (weekly consumption) } \\
\hline & $0,5-1$ & $1-2$ & over than 2 & No reply & No & Total \\
\hline \multirow[t]{2}{*}{ Male } & 15 & 64 & 17 & 5 & 28 & 129 \\
\hline & $11.60 \%$ & $49.60 \%$ & $13.20 \%$ & $3.90 \%$ & $21.70 \%$ & $100.00 \%$ \\
\hline \multirow[t]{2}{*}{ Female } & 23 & 62 & 24 & 6 & 45 & 160 \\
\hline & $14.40 \%$ & $38.80 \%$ & $15.00 \%$ & $3.80 \%$ & $28.10 \%$ & $100.00 \%$ \\
\hline \multirow[t]{2}{*}{ Education Fac. } & 21 & 85 & 26 & 1 & 44 & 177 \\
\hline & $11.90 \%$ & $48.00 \%$ & $14.70 \%$ & $0.60 \%$ & $24.90 \%$ & $100.00 \%$ \\
\hline \multirow[t]{2}{*}{ Science-Art Fac. } & 12 & 33 & 9 & 8 & 25 & 87 \\
\hline & $13.80 \%$ & $37.90 \%$ & $10.30 \%$ & $9.20 \%$ & $28.70 \%$ & $100.00 \%$ \\
\hline \multirow[t]{2}{*}{ Eng.Fac. } & 5 & 7 & 6 & 2 & 4 & 24 \\
\hline & $20.80 \%$ & $29.20 \%$ & $25.00 \%$ & $8.30 \%$ & $16.70 \%$ & $100.00 \%$ \\
\hline \multirow[t]{2}{*}{ General } & 38 & 126 & 41 & 11 & 73 & 289 \\
\hline & $13.10 \%$ & $43.60 \%$ & $14.20 \%$ & $3.80 \%$ & $25.30 \%$ & $100.00 \%$ \\
\hline
\end{tabular}

Table 5: Bread consuming ratio as daily (acc. to faculty and sex)

\begin{tabular}{|c|c|c|c|c|c|c|}
\hline \multirow[b]{2}{*}{ Gram } & \multicolumn{6}{|c|}{ Daily bread consumption } \\
\hline & No & $0-250 \mathrm{~g}$ & $251-500 \mathrm{~g}$ & Over than $500 \mathrm{~g}$ & No reply & Total \\
\hline \multirow[t]{2}{*}{ Male } & 1 & 1 & 4 & 121 & 2 & 129 \\
\hline & $0.80 \%$ & $0.80 \%$ & $3.10 \%$ & $93.80 \%$ & $1.60 \%$ & $100.00 \%$ \\
\hline \multirow[t]{2}{*}{ Female } & 16 & 10 & 54 & 73 & 7 & 160 \\
\hline & $10.00 \%$ & $6.30 \%$ & $33.80 \%$ & $45.60 \%$ & $4.40 \%$ & $100.00 \%$ \\
\hline \multirow[t]{2}{*}{ Education Fac. } & 8 & 4 & 39 & 125 & 1 & 177 \\
\hline & $4.50 \%$ & $2.30 \%$ & $22.00 \%$ & $70.60 \%$ & $0.60 \%$ & $100.00 \%$ \\
\hline \multirow[t]{2}{*}{ Science-Art Fac. } & 8 & 5 & 14 & 54 & 6 & 87 \\
\hline & $9.20 \%$ & $5.70 \%$ & $16.10 \%$ & $62.10 \%$ & $6.90 \%$ & $100.00 \%$ \\
\hline \multirow[t]{2}{*}{ Eng.Fac. } & 1 & 2 & 5 & 14 & 2 & 24 \\
\hline & $4.20 \%$ & $8.30 \%$ & $20.80 \%$ & $58.30 \%$ & $8.30 \%$ & $100.00 \%$ \\
\hline \multirow[t]{2}{*}{ General } & 17 & 11 & 58 & 194 & 9 & 289 \\
\hline & $5.90 \%$ & $3.80 \%$ & $20.10 \%$ & $67.10 \%$ & $3.10 \%$ & $100.00 \%$ \\
\hline
\end{tabular}

Table 6: Alcoholic beverage consuming ratio as weekly (acc. to faculty and sex)

\begin{tabular}{|c|c|c|c|c|}
\hline & I do not consume alcoholic beverage & I consume alcoholic beverage & No reply & Total \\
\hline \multirow[t]{2}{*}{ Male } & 77 & 48 & 4 & 129 \\
\hline & $59,70 \%$ & $37,20 \%$ & $3,10 \%$ & $100,00 \%$ \\
\hline \multirow[t]{2}{*}{ Female } & 127 & 24 & 9 & 160 \\
\hline & $79,40 \%$ & $15,00 \%$ & $5,60 \%$ & $100,00 \%$ \\
\hline \multirow[t]{2}{*}{ Education Fac. } & 141 & 35 & 1 & 177 \\
\hline & $79,70 \%$ & $19,80 \%$ & $0,60 \%$ & $100,00 \%$ \\
\hline \multirow[t]{2}{*}{ Science-Art Fac. } & 48 & 30 & 9 & 87 \\
\hline & $55,20 \%$ & $34,50 \%$ & $10,30 \%$ & $100,00 \%$ \\
\hline \multirow[t]{2}{*}{ Eng.Fac. } & 15 & 7 & 2 & 24 \\
\hline & $62,50 \%$ & $29,20 \%$ & $8,30 \%$ & $100,00 \%$ \\
\hline \multirow[t]{2}{*}{ General } & 204 & 72 & 13 & 289 \\
\hline & $70,60 \%$ & $24,90 \%$ & $4,50 \%$ & $100,00 \%$ \\
\hline
\end{tabular}

Table 7: Preferring the shopping section attitude (acc. to sex)

\begin{tabular}{|c|c|c|c|c|c|}
\hline & Electrical kitchen equipment, electronic, souvenir items & Food & Cosmetic & Clothing & No reply \\
\hline \multirow[t]{2}{*}{ General } & 29 & 127 & 25 & 45 & 63 \\
\hline & $10.00 \%$ & $43.90 \%$ & $8.70 \%$ & $15.60 \%$ & $21.80 \%$ \\
\hline \multirow[t]{2}{*}{ Female } & 6 & 72 & 21 & 30 & 31 \\
\hline & $3.80 \%$ & $45.00 \%$ & $13.10 \%$ & $18.80 \%$ & $19.40 \%$ \\
\hline \multirow[t]{2}{*}{ Male } & 23 & 55 & 4 & 15 & 32 \\
\hline & $17.80 \%$ & $42.60 \%$ & $3.10 \%$ & $11.60 \%$ & $24.80 \%$ \\
\hline
\end{tabular}

It is shown that $25 \%$ of university students consume alcoholic beverages. Based on the sex criteria, woman's consume alcohol as $15 \%$ and mans consume as $37 \%$. Based on the faculty criteria, alcohol consuming in students in Education Faculty (Science Education) is $20 \%$ of level, in Science and Art Faculty (Chemistry, Biology, Physic Departments) is 35\% of level and in Engineering Faculty (Food Engineering) is $30 \%$ level of consuming (Table 6).
In the scope of our research, $45 \%$ of university students consume coffee as daily habit. Based on the sex criteria of evaluation, woman's' coffee consuming as $50 \%$ and mans' consuming as $40 \%$. According to faculty criteria, daily coffee consuming in students in Education Faculty (Science Education) is 36\% of level, in both Science and Art Faculty (Chemistry, Biology, Physic Departments) and Engineering Faculty (Food Engineering) is $68 \%$ of level. 
According to Table 7; preferring the shopping section attitude (Acc. to sex) of university students. However university students generally interested in "food section" and "clothing section", based on the evaluation regarding sex criteria, man more concern with the "electronic and souvenir items section" and woman's more prefer the "clothing section". Moreover, women prefer "cosmetic section" in shopping (Table 7).

\section{DISCUSSION}

Currently, human alternate their nutrition habits and confer the consuming processed foods and tendency to consuming the alcoholic beverages in their technological supported life. As a result of this, it is formed the "showing off" consuming. Our research is accordance with these concepts ${ }^{[1,6]}$. Excessive bread consuming is indicator of the urbanization and revenue level. As a similar result from our research, bread consuming in Manisa Celal Bayar University, Education Faculty students has been reached to high ratio $(95 \%)$.

According to the questionnaire applied to university students of 400 accommodated at home and student dormitory in Istanbul city (Turkey), students' primary consume tea as beverage in their breakfast, followed fruit juices ${ }^{[7]}$. This result is accordance with our findings.

In investigation concerning milk and yogurt consuming of working willing people including 131 female, 87 of male at Ankara, it is determined that $32 \%$ of people prefer hot coffee as beverage whereas $13.3 \%$ of people prefer cold coffee. According to sex criteria, coffee-consuming style is varied from male to female. Man prefer as hot $(35,5 \%)$ whereas woman's prefer as cold $14 \%^{[8]}$. In our investigation, it is reported that coffee consuming habit is about $50 \%$ of level. Based on the sex criteria, coffee consuming is $56 \%$ for female and this score is higher than male group (43\%).

With the excessive bread consuming in all faculty criteria and all male categories (99\%) it has been demonstrated that Turkish Society urbanized rapidly. Among all the food products in Turkey, bread is more produced $^{[9]}$ and is more wasted ${ }^{[10]}$. This situation is meaningful due to it is the reflection of the "Turkish consumer conscience".

Labeling in food products is crucial for producer and especially for consumer and it is stated continuously in media ${ }^{[11]}$. In our research, university students formed the intellectual section of society not demonstrate adequately perception concerning labeling, this situation is indicator of insufficient "consumer conscience" as nutrition culture.

Advertisements effect in food preferring is important and it is reverse with upper socialeconomical status and intellectual level of people ${ }^{[12]}$. This finding is accordance with our results.
In our research, general concepts regarding foods and processed foods, formation process of these concepts, attitudes concerning some foods and beverages were examined. Concepts on food preservation, food selling area, labeling in food products, advertisements, safety and artificial foods based on faculty and sex criteria were determined using multiply regression analysis. Besides, the examining of daily, weekly, monthly consumption of basic food items, hot and cold beverages were evaluated. All results were accordance with the research reported by Yilmaz and Demirci ${ }^{[7]}$.

In food preferring of Manisa Celal Bayar University students based on faculty criteria, there is significant results $(p>0.01)$. Science and Art Faculty students' thinks that artificial foods are danger whereas Engineering Faculty students report that these foods may be consume. This situation shows the "consumer conscience difference" between the students learned food education and not. Otherwise, this situation is also indicator that cultural constituents in Turkish society and intellectual properties of persons are oppressed with various levels.

Tea is valuable crop in Turkey, according to 1998 data, the production of tea leaves was 600000 ton and dry tea was 144540 ton (in world $6^{\text {th }}$ ) and export value was $1.314 .110 \mathrm{~kg}$. Tea consuming is popular in Turkey. According to 1993 data, it is reported that annual consuming was 124.000 metric ton ${ }^{[13]}$. In our research based on the questionnaire, in especially male, tea consuming preferring is high ratio (98\%) due to the cost is low and its nutritive effects is good and it is refresh the body.

According to general results of our research, university students as intellectual section of Turkish society are not adequate concerning the sufficient and balanced nutrition. Our suggestion in this matter, to study regarding the "food conscience" together with visual and written media vehicles including TV, newspaper and journals etc., to organize symposium, panel and conference concerning "food conscience" and "food safety" and to propose knowledgeable lessons in all level of education institution.

\section{REFERENCES}

1. Acar, A., 2000. Gösteriş Tüketimi, Standart (457).

2. Anonymous, 2003. The Food Guide Pyramid. http://www.nal.usda.gov:8001/py/pmap.htm. Accessed on 05.04.2003

3. Anspaugh, D.J., M.H. Hamrick and F.D. Rosato, 1997. Wellness: Concepts and Applications. New York: Mosby-Year Book, Inc.

4. Giddens, A., 2000. Sociology. Edit.Ozel, H. Guzel C. Ayraç Bookseller, Ankara, (In Turkish). 
5. Gordon, M., 1999. Sociological food examination matter. In: The Dictionary of Sociology. Transl. Akınay O., Kömürcü, D. Science and Art Publ., Ankara, (In Turkish).

6. Sürücüoğlu, M.S., 1999. Beslenme ve Sağlığımız, Standart (448) (In Turkish).

7. Yllmaz, İ. and M. Demirci, 2001. Üniversite Öğrencilerinin Beslenme Alışkanlıkları, Gıda (In Turkish).

8. Özçelik, Ö. and P. Çakıroğlu, 1999. Çalışanların Süt, Yoğurt, Peynir Tüketim Alışkanlıkları, Standart (448) (In Turkish).

9. Emiroğlu, M., 1998. Türk Gıda Sanayi ve Gıda Standartları, Standart (441) (In Turkish).
10. Gümüş, S., 2000. Ekmeğin Değerlendirilmesi Sorunu ve Çözüm önerileri, Standart (458) (In Turkish).

11. Ölmez, M., 2000. Su Ürünleri ve İnsan Sağlı̆̆1, Standart (466) (In Turkish).

12. Nazik, M.H. and N. Şanlıer, 2000. Ailelerin Tüketim Davranışlarına Reklamların Etkisinin Tespiti Üzerine Bir Araștırma, Standart (476) (In Turkish).

13. Tokuşoğlu, Ö., 2001. The Determination of the Major Phenolic Compounds (Flavanols, Flavonols, Tannins) and Aroma Properties of Black Teas. Ph.D.Thesis. University of Ege, Bornova, Izmir, Turkey. 